- researchers - who were either at contract research labs or at core facilities in academic institutions - were not allowed to deviate from the peer-reviewed protocols that they had agreed at the start of their experiments (in consultation with the original authors). So they simply reported the problem. Doing anything else - such as changing the experimental conditions or restarting the work - would have introduced bias, says Errington.

Such conflicts mean that the replication efforts are not very informative, says Levi Garraway, a cancer biologist at the Dana-Farber Cancer Institute in Boston, Massachusetts. "You can't distinguish between a trivial reason for a result versus a profound result," he says. In his study, which identified mutations that accelerate cancer formation, cells that did not carry the mutations grew much faster in the replication effort ${ }^{7}$ - perhaps because of changes in cell culture. This meant that the replication couldn't be compared to the original.

\section{DEVIL'S IN THE DETAILS}

Perhaps the clearest finding from the project is that many papers include too few details about their methods, says Errington. Replication teams spent many hours working with the original authors to chase down protocols and reagents, in many cases because they had been developed by students and postdocs who were no longer with the lab. Even so, the final reports include long lists of reasons why the replication studies might have turned out differently - from laboratory temperatures to tiny variations in how a drug was delivered. If the project helps to bring such confusing details to the surface, it will have performed a great service, Errington says.

Others think that the main value of the project is to encourage scepticism. "Commonly, investigators take published results at face value and move on without reproducing the critical experiments themselves," says Glenn Begley, an author of the 2012 Amgen report.

That's not the case for Albrecht Piiper, a liver-cancer researcher at the University Hospital Frankfurt in Germany. Piiper has replicated Ruoslahti's work in his own lab . Despite the latest result, he says, he has "no doubt" about the validity of Ruoslahti's paper. $\approx$ SEE EDITORIALP.259

1. Sugahara, K. N. et al. Science 328, 1031-1035 (2010).

2. Begley, C. G. \& Ellis, L. M. Nature $\mathbf{4 8 3}, \mathbf{5 3 1 - 5 3 3}$ (2012).

3. Mantis, C. et al. eLife 6, e17584 (2017).

4. Aird, F. et al. elife 6, e21253 (2017)

5. Kandela, I. et al. eLife 6, e17044 (2017).

6. Horrigan, S. K. et al. eLife 6, e18173 (2017)

7. Horrigan, S. K. et al. eLife 6, e21634 (2017).

8. Schmithals, C. et al. Cancer Res. 75, 3147-3154 (2015).

\title{
PUBLISHING
}

\section{Gates Foundation demands open access}

\section{Global-health charity clashes with leading researchjournals.}

\section{BY RICHARD VAN NOORDEN}

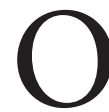
ne of the world's most influential global health charities says that the research it funds cannot currently be published in several leading journals, because the journals do not comply with its open-access policy.

Scientists who do research funded by the Bill \& Melinda Gates Foundation are not for the moment - allowed to publish papers about that work in journals that include Nature, Science and the New England Journal of Medicine (NEJM). (Nature's news team is editorially independent of its research team.)

The bar is a result of the Gates Foundation's policy in support of open access and open data, which was first announced in 2014 but came into force at the beginning of 2017. "Personally, I applaud the Gates Foundation for taking this stance," says Simon Hay, a Gatesfunded researcher who is director of geospatial science at the Institute for Health Metrics and Evaluation in Seattle, Washington. "The overwhelming majority of my colleagues in global health and fellow Gates grantees with whom I have chatted are highly supportive of these developments," he says.

\section{OPEN-ACCESS CLASH}

The foundation, which is headquartered in Seattle, stipulates that the researchers whom it funds must make open their resulting papers and underlying data sets immediately upon publication. And papers must be published under a licence that allows unrestricted reuse - including for commercial purposes.

But some journals do not offer this kind of open-access (OA) publishing. Many of them allow papers to be made free to read after an embargo period, usually of around six months, and let authors upload accepted manuscripts online. But neither policy meets the Gates Foundation's requirements. And so, for papers submitted from the start of 2017, a few prominent journals are currently off limits to Gates-funded academics.

Dick Wilder, associate general counsel with the charity's Global Health Program, says that the foundation does not plan to allow exceptions to its policy.

The clash will affect only a few hundred research papers. The foundation typically sees around 2,000-2,500 papers published each year from its funding, says Wilder, of which $92 \%$ are published in journals that comply with its OA policy.

Still, the discussions could result in influential journals making special arrangements with the Gates Foundation to permit OA publishing. If that happens, it would be the first time that journals such as Nature and Science have allowed a group of scientists an open-access publishing route on the basis of their funding source.

In 2008, many journals were unwilling to accommodate a US National Institutes of Health (NIH) policy, which, at the time, mandated that papers be made freely available no later than 12 months after publication, notes Peter Suber, director of the Harvard Open Access Project and the Harvard Office for Scholarly Communication in Cambridge, Massachusetts. In the end, publishers accommodated the policy, notes Suber, who expects that the Gates policy "Personally, will draw the same I applaud the Gates Foundation for taking this stance." concessions from publishers.

Another private medical funder, the Wellcome Trust in London, UK, also mandates OA publishing. But its policy permits a six-month embargo on making published papers open. When asked whether Wellcome would change its policy if journals were to accommodate the Gates Foundation requirements, its head of digital services, Robert Kiley, said: "We'll be watching this development closely."

\section{JOURNALS' VIEW}

A spokesperson for Nature's publisher, Springer Nature, noted that most of its journals already comply with the Gates Foundation policies and that Nature and Nature-branded titles make it possible to share links to freely access papers through an online reader.

The American Association for the Advancement of Science, which publishes the Science family of journals, says that it is "in discussions with the Gates Foundation on this matter", and the NEJM says that "the policy of the Gates Foundation is under active discussion". . 